\section{氮化熔鉄催化剂流动床合成的 冷凝水中的含氧化合物的組成}

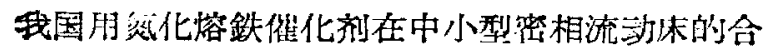
成試驗上已得到主好的結果 $[1,2]$ 。本文报道上項催化 剂在中型試驗中，在反应 400 -600 小时關所生成的



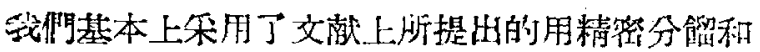
化学分析相結命的綜合方法[3,4]，但进一步采用了初



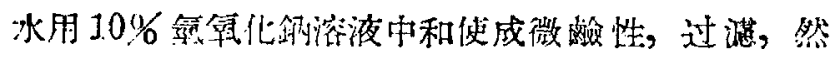

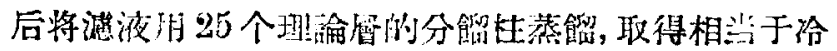
㠜水重 $11.0 \%$ 的、沸点在 $96^{\circ} \mathrm{C}$ 以下的濃樎物，其折 含有 78.3\%的中性含氧化合物。底液中䐘基含量仅为

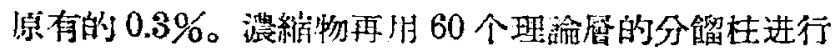
分的，获得沸点为(I) $53.7-62^{\circ}$ 、(II) $62-70^{\circ}$ 、(III)

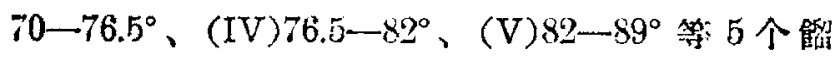
份，各占濃縮物重量的 $4.0 \% 、 7.2 \% 、 2.2 \% 、 3.3 .9 \%$ 。

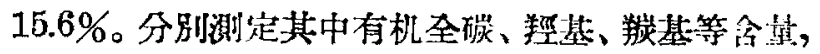
从而可計算出各镏份的中性含氧化合物的总含最各 沩 (I) $90.7 \%$ 、(II) $98.6 \%$ 、(III) $95.9 \%$ 、(IV) $89.5 \%$ （V) 64.9 。再取沸点为 $64^{\circ} 、 78^{\circ} 、 87^{\circ}$ 的餾

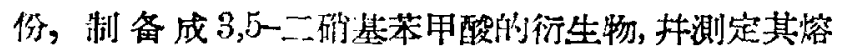


数据，可認为镏份 (I) 中含有两酮，(II)、(III) 中 含侍丁醏，(III)的含有乙醇，(IV)中含有戊酳，(V)

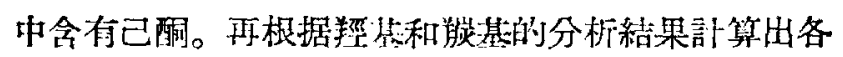
镏份朴中性全氧化合物总含量各为 (I) $88.7 \%$ （II） 98.7、(III) $102.9 、$ (IV) $87.2 \%$ （V) $65.3 \%$ 。这

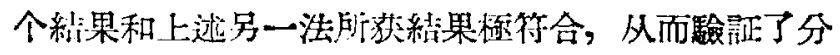
析結果的可靠性（镏份 III相差 7\% 是由于其中含 有甲㜔，但团为（III）的絕对量很少，对最后結果 影响不大，故可忽略）。腈类似方法分析底液中所含 有的有机酸，即先将底液濃緥、酸化，用乙梄多次抽 提出其的含有的有机酸。用 60 个理論憎的分馏柱除

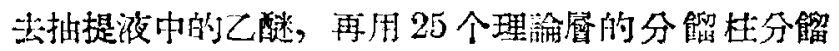
所特酸取得窄镏份。从各锴份的酸价和奎碳分析結 果，証明無甲酸存在。116-117.5 $5^{\circ}$ 及 $140.5-142^{\circ}$ 的

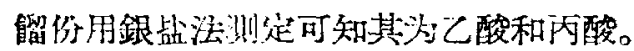

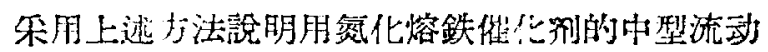
林合成的冷凝水中会有 $8.6 \%$ 的中性会牮化合物和 $0.44 \%$ 的酸性会氧化合物。其中主要产品为乙醇 1.4\%、两醇 $1.9 \%$ 、甲醇 $0.9 \%$ 、离粐酸 (丁醇以上)

$0.7 \%$ 、丙酮、戊酮备为 $0.2 \%$ 、乙酸 $0.3 \%$ 。

当催化剂組成改变时会影响水相含氧化合物的維
成。当用破含量㜞高的催化剂在小型流呩休合成时， 在冷凝水中含有 $9.8 \%$ 中性含氧化合物和 $8.3 \%$ 酸性含 翌化合物。主要成份为: 乙醇 $7.3 \%$ 、乙酸 $5.2 \%$ 、丙 醇 $1.5 \%$ 、丙酸 $1.1 \%$ 、高般酸（丁酸以上） $2.0 \%$ 、

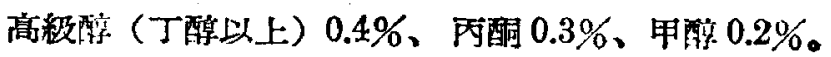
管荣林卢偑章 (中国科学院石油旰㤎所) 1957 年 2 月 6 日

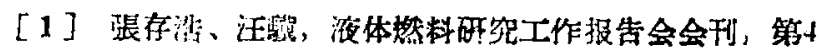
页，中形科学院，1954。

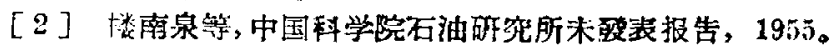

[3] A. Н. Башкиров, М. М. Хотимская и Н. А. Орлова, Труды Ии-та Нефти, АН СССР, 6, 135 (1955).

[4] A. Steitz and D. K., Barnes, Ind. Eng. Chem., $45,353(1953)$.

\section{鯉魚鱗片年輪的标志 及其形成的时期}

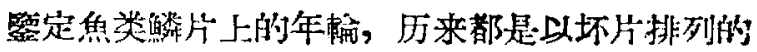
疏滵为依据。一般哂为春夏季鱗片生长迅速，生成的 环片排列較稀䟽; 秋冬季生长緩慢，生成的环片排列 較紧密，当年排列紧復部份和次年排列稀疏洌份之開 的分界䋨就标志着年輸。Чугунова (1952) 在“焦类年 命和生长的研究方法”[1]一書中，也把这种兒解当作 一般法则。关于鲤魚魴片上的年輪，Hoffbauer (2)

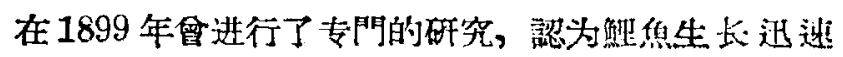
时，鳞片上环片間的距离越大，排列得越不梘則。

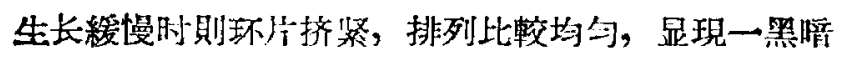
区域，这就是一年的界限。这种概念，一直保留到現 代, 像Pincher (1948) 的“焦类知識” [3] 就是特这 样的特征腹明鯉且的年輸的。

1955年，我們对梁子湖䱇焦鱗片上的年輪作了部

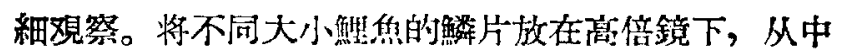

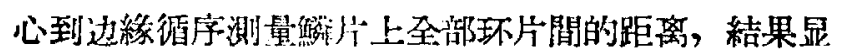
示，一年中环片排列的疏嗐浑有任何季节性的規律变 化，因此环片排列的疏潘不能反映鮭围的年令。同时 也找出标志年輸的，是一利时于环片群走向不同而引 起的环片切割現象。这现象在醂片“側部”和“后部”的 交界处表現坟淙造，其次是在“側部”和“前部”的交界 处。在场制处有的㳅有以下情况出現: (1) 有 2-3 圆 环片断裂，排列显得凌乱; (2) 缺少 1-2 圈环片, 出現一空白区; (3) 2-3 圈环片排列紧密, 形成一黑: 圈。因此环片排列的疏㓡只是年輪的附屈特征，而足以 标志年棆的是环片的切割現像 (晃下圖)。

这和礿到是否能代表年輸，已从焦获物的长庭变

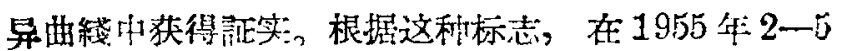




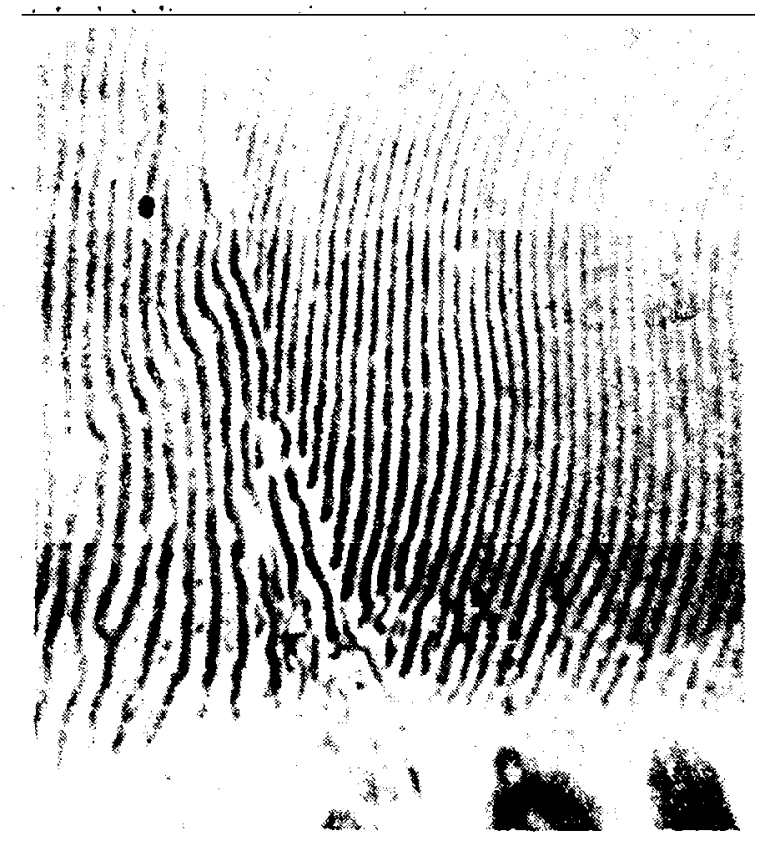

月測定魚获物年令的洁果，二冬令焦(具有一个年腀) 的长度以 34 厘米的最多，三冬命魚（具有二个年腀） 以 47 厘米最多。同时期中取另一批囪（560 条）的

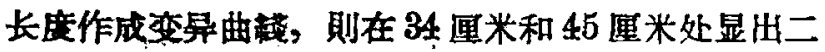
个显著的飄。

年蝓形成的时期：逐月检查觶片的結果，証明触 魚年积形成的季节不是冬季而是夏季。从 1955 年 2

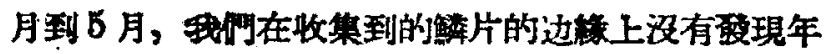
陯，而在 6 月份检查的 97 条魚中有 8 条魚的铁片具

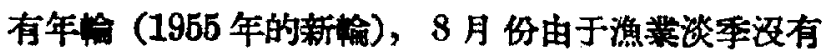
取得样本，9月所䅞到的大批境本中，全部边線暗有 年倫。1955 年梁子湖䚛魚大批产卯是 5一6月, 而新年 哈形成則在生殖节后的 7-8 月。由此可見, 冬季是

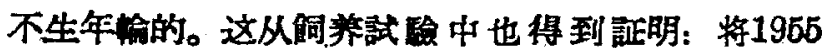
年的魚苗姛美在实猃魚池中，至 1956 年取出，检查

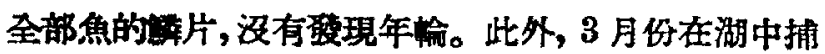
起的纤触（长度为 16-23 無米），也全部沼有年輪。

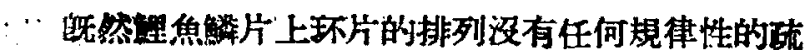

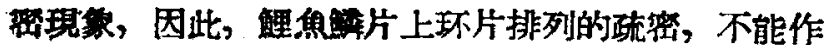

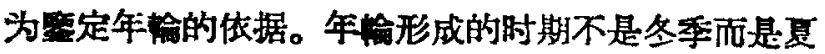
季，而且是在生殖期以后。这榜看来，鲤魚的年陯是 和生殖陯相符合的。这和 Чугунова 所研究的鮩魚 (Rutilus rutilus) 情况相似。

\section{陈姵薯}

（中国样学院水生生物研究所） 1957 年 2 月 14 日

[1] Н. И. Чугунова, Методика изучония возраста и роста раб, Совотская наука, Москва, 1952.

[2] C. Hoffbauer, Die Altersbestimmung des Karpfen an seiner Schuppe, Jahreshericht des Schlesischen Fischerei-Vereins fur Jahr 1899, 1899.

[3] C. Pincher, A Study of Fish, New York, 1948.

\section{$1901-1950$ 年时期中我国部分 地区降水偏距的統計研究}

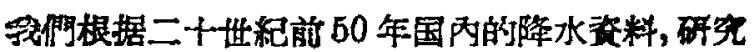
了长江中下游、东南沿海地带、渤海周图地区在該时 期中普遍出現水旱的月份。历年逐月各地的降水量㤝 料皆可分为七数，第一級降水最少，第七极降水最 多。[1] 每个地区普掘出現第一、二耓的降水时称为平 月，普遍出現第六、七級的降水时称为水月。50 年中 三个地区出現水旱月份的頻数如下:

\begin{tabular}{|c|c|c|c|c|c|c|}
\hline & \multicolumn{2}{|c|}{ 长江区 } & \multicolumn{2}{|c|}{ 勃 海 区 } & \multicolumn{2}{|c|}{ 东席沿酒区 } \\
\hline & & 水月 & 旱月 & 水月 & 卓月 & \\
\hline 1月 & 6 & 3 & 11 & 2 & 12 & 4 \\
\hline 2月 & 7 & 4 & 12 & 0 & 10 & 4 \\
\hline 3月 & 1 & 4 & 10 & 5 & 7 & 2 \\
\hline 4月 & 4 & 5 & 8 & 5 & 6 & 3 \\
\hline 5月 & 3 & 2 & 2 & 4 & 4 & 3 \\
\hline 6月 & 4 & 3 & 6 & 4 & 4 & 2 \\
\hline 7月 & 8 & 2 & 3 & 1 & 6 & 7 \\
\hline 8月 & 6 & 2 & 4 & 4 & 4 & 2 \\
\hline 9月 & 5 & 0 & 6 & 2 & 6 & 2 \\
\hline 10月 & 9 & 4 & 4 & 4 & 14 & 0 \\
\hline 11月 & 9 & 4 & 10 & 4 & 13 & 1 \\
\hline 12月 & 12 & 6 & 5 & 4 & 14 & 4 \\
\hline 合 計 & 74 & 39 & 81 & 39 & 100 & 3 \\
\hline
\end{tabular}

可見每个地区出現的旱月皆比水月为多，每 10 年

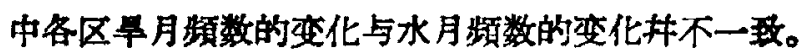

\begin{tabular}{|c|c|c|c|c|c|c|}
\hline \multirow{2}{*}{ 策 } & \multicolumn{2}{|c|}{ 玄 江 区 } & \multicolumn{2}{|c|}{ 勃酒区 } & \multicolumn{2}{|c|}{ 经用沿㴗区 } \\
\hline & 基自 & 水月 & 早月 & 水月 & 卓月 & 水月 \\
\hline $1901-1910$ & 17 & 10 & 14 & 4 & 25 & $?$ \\
\hline $1911-1920$ & 10 & 10 & 18 & 9 & 19 & 7 \\
\hline $1921-1930$ & 17 & $\mathbf{3}$ & 18 & 6 & 20 & 7 \\
\hline $1931-1940$ & 17 & 11 & 20 & 11 & 23 & 6 \\
\hline $1941-1950$ & 13 & 5 & 11 & 9 & 13 & 7 \\
\hline 偖 & 74 & 39 & 81 & 39 & 100 & 34 \\
\hline
\end{tabular}

三个此区历年仙現水旱月份的多少也不均与, 每 个地区每年出現水早月次数所占的年数如下:

\begin{tabular}{|c|c|c|c|c|c|c|}
\hline 㺲年的現头数 & $\begin{array}{l}\text { 长 } \\
\text { 卓月 }\end{array}$ & $\begin{array}{c}\text { 区 } \\
\text { 水月 }\end{array}$ & $\begin{array}{c}\text { 勃 } \\
\text { 早月 } \\
\end{array}$ & $\begin{array}{l}\text { 区水角 } \\
\end{array}$ & $\begin{array}{l}\text { 东用 } \\
\text { 早月 } \\
\end{array}$ & $\begin{array}{l}\text { 海区 } \\
\text { 水月 }\end{array}$ \\
\hline 0 & 11 & 24 & 10 & 21 & $\mathbf{5}$ & 22 \\
\hline 1 & 15 & 18 & 20 & 21 & 16 & 23 \\
\hline 2 & 16 & 4 & 10 & 6 & 13 & 4 \\
\hline 3 & 5 & 3 & 5 & 2 & 8 & 1 \\
\hline 4 & 3 & 1 & 1 & 0 & 6 & 0 \\
\hline$j$ & 0 & 0 & 2 & 0 & 2 & 0 \\
\hline 6 & 0 & 0 & 2 & 0 & 0 & 0 \\
\hline 合計年数 & 50 & 50 & 50 & 50 & 50 & 50 \\
\hline
\end{tabular}

水旱月的季节分布，各地区關有一定的差异。 国出現降水异常的年份与大范䍗环流状况的变 